\title{
Difficulties and Performance in Mathematics Competences: Solving Problems with Derivatives
}

\author{
https://doi.org/10.3991/ijep.v10i4.12473 \\ Verónica Díaz Quezada \\ Universidad de Los Lagos, Osorno, Chile \\ mvdiaz@ulagos.cl
}

\begin{abstract}
The aim of this research are to assess the performance of engineering students when using mathematical competences to solve problems with derivatives, to analyze their difficulties, and to observe which secondary school contents are essential for this purpose. The study is descriptive and exploratory with the use of quantitative methods. The participants are students of three competence-based engineering programs of a Chilean University. According to the diagnostic test, the results show a limited knowledge of secondary education mathematical contents like algebra, the main mathematical functions, and proportional geometry. According the research results the presence of difficulties associated to mathematical thinking processes and the complexity of mathematical objects are also evident. However, everyday problems fantasy context were more appealing for students, who solved most of them correctly. Even though these problems are imaginary, they were formulated using situations that engineering students face every day.
\end{abstract}

Keywords-Mathematical competences, problem solving, derivatives, difficulties, engineering programs, higher education

\section{Introduction}

The scope of Mathematics Education goes from the most basic mathematical notions to the complex mathematics taught in Universities. From its epistemic, didactic, and cognitive aspects, its objective is to train people who will be able to solve problems in their different expertise areas [1], especially in engineering. Several studies in the field have address the problem of improving teaching practices with the implementation of pedagogical strategies aimed at overcoming student's difficulties with the understanding of concepts like limits, derivatives, and integrals [2-7]. Even though different Calculus courses may have different objectives in higher education, all of them are mainly centred on algorithms and traditional methods of mathematics teaching [8]. With these methods students manage to be able to use integrals, derivatives, and basic limits, but they are unable to extrapolate these notions to a wider context. The mechanical methods by which they were taught prevail [9]. 
There are investigations that have confirmed that in undergraduate Mathematics, when these courses are taught they have different difficulties that can be both pedagogical, epistemological and even psychological. [9-14]. Teachers complain that students are unable to understand and relate the main contents of these courses that they have continuity, derivatives and integrals [15-17]. In different countries, mathematics teachers have made efforts to redesign calculus classroom instruction recognizing its importance [18], because the consensus is that this it is a difficult subject for students [19]. This seems to cause negative consequences, even more when students need knowledge and abilities to solve real problems in their careers [20].

The authors [7] [21] provide one of the first descriptions of the difficulties that students have with derivatives. Even when students in general were competent in the calculation of derivatives, significant difficulties were found on exchange rate and the representation of this mathematical object. These were frequently linked to an insufficient or incorrect comprehension of limits, relation, function and proportionality. In our opinion, they need to develop competences like solving problems with the use of derivatives, but prior to that, they need basic knowledge from secondary education that support derivation, like algebra, geometry, and trigonometry. This is the case of engineering students, such as students of Food Engineering, Computer Engineering and Commercial Engineering.

In a decade when the value of university education is under permanent quality assessment, this research was devised to address the performance of the competence of solving of problems of derivatives and its applications, and the difficulties that students have when solving them. It was also relevant to consider students' prior knowledge and abilities that allowed them to study engineering in a public Chilean university, as a baseline for this assessment. Our research questions are the following: What are the mathematical concepts that cause difficulties to students before studying engineering? Do students of engineering programmes have the mathematical competences required to solve problems with the use of derivatives? What difficulties arise when solving these problems? From these research problem and questions, of similar results in research of types of limit problems of a real function in four engineering programs, we designed this study for three engineering programmes.

The objective of this research was to observe the competences required to solve problems with the use of derivatives. The specific objectives were (1) to use a standardised diagnostic assessment instrument that was designed using the current curriculum required to start higher education; (2) to design, validate and administer an instrument to assess mathematical competences for the application of derivatives; (3) to determine and to analyse the performance of students on different types of mathematical competences; (4) to analyse the difficulties that arise when solving problems that require the use of derivatives.

\section{Theoretical Framework}

Several difficulties associated with the mathematical object derivative have been observed from different theoretical perspectives [18] [22]. However, understanding this 
mathematical notion from a local perspective is still an unsolved problem. One of the main research topics on the comprehension of derivatives is its algorithmic use and practice. [23] states that the difficulties with derivatives of students that fail may arise from the lack of basic mathematical knowledge. The theoretical framework of this research has two main foundations: problem-solving difficulties linked mathematics learning according to [24] and the types of mathematical competences of [25-27].

\subsection{Difficulties}

For [24] the nature of learning difficulties in mathematics in general has different sources. They say that their origin is in the educational microsystem that comprises student, teacher, curriculum and school. Therefore, the difficulties could be addressed from different perspectives, depending on where the focus needs to be. These difficulties are connected and strengthened by complex networks that in practice constitute obstacles that are materialized in the form of errors. For [24] difficulties could be classified in five categories: the first two are associated with subject-specific criteria (mathematical objects and thinking processes), the third one is mathematics teaching processes, the fourth is related to the cognitive processes of students, and the fifth is the lack of a rational attitude towards mathematics.

For this study, the following four sources of difficulty from the theoretical framework were considered: (1) Difficulties related to the complexity of mathematical objects: it is related with the use of language in the comprehension and communication of mathematical objects and everyday language as a having a mediating role in the interpretation of signs. (2) Difficulties related to the mathematical thinking processes: it is related to the implicit breaks in the modes of mathematical thinking: examples, drawings on the board, or standardized images could cause errors. (3) Difficulties related to the mathematics teaching processes: the teaching methods should meet the standards of the school and the curriculum and (4) Difficulties related to the cognitive development of students: the different stages of cognitive development of students, their characteristics and abilities, must be considered when designing the resources and teaching strategies.

\subsection{Mathematical competences for problem solving}

Mathematical competences can be fostered as part of thinking processes that allow the understanding of problematic situations and the use of information in different contexts [28]. The mathematical competence can be conceptualised as the set of abilities and skills related to the comprehension and interpretation of problems in different contexts (family, social, academic or professional situations), its translation into language and mathematical contexts, its solving using the appropriate mathematical procedures, the interpretation of its results, and the formulation and communication of them [29]. Regarding the problem-solving competence, [30] define it as taking on a task to which the method to solve it is unknown [31]. According to this definition, then we can deduce that there are as mathematical tasks those that constitute a problem and another that does not, that is, they would be routine tasks or exercises. [32, 33]. 
The authors [34, 35] have brought up questions about how students face problem solving and the processes that lead them to a solution. Scholars have tried to find answers to the questions of [35] investigating how they solve different types of engineering problems also in to context [36-38]. However, according to \{39-42, research on problem solving in engineering has focused its attention on developing skills, without considering the influence of personal contexts and situations that may foster students' motivation and performance during the process [43] in general, and in secondary education in particular. According to [44], one important aspect of the mathematical competence is that mathematics is used to solve problems in context [44]. Context is the aspect of an individual's world where problems are situated. The selection of strategies and appropriate mathematical representations commonly depends on the context where the problem is presented.

\subsection{Types of mathematical competences}

Mathematics competences can be fostered as part of thinking processes that allow the understanding of problematic situations and the use of information in different contexts [28]. The current challenge is making students develop mathematic competences that are considered essential in the curriculum through school years. These integrate skills, knowledge, and abilities that cause a positive attitude towards the comprehension of a problem and the ability to implement solving processes [45]. The classification of types of mathematical competences of [25-27], which is part of the theoretical framework, is presented in fig. 1 .

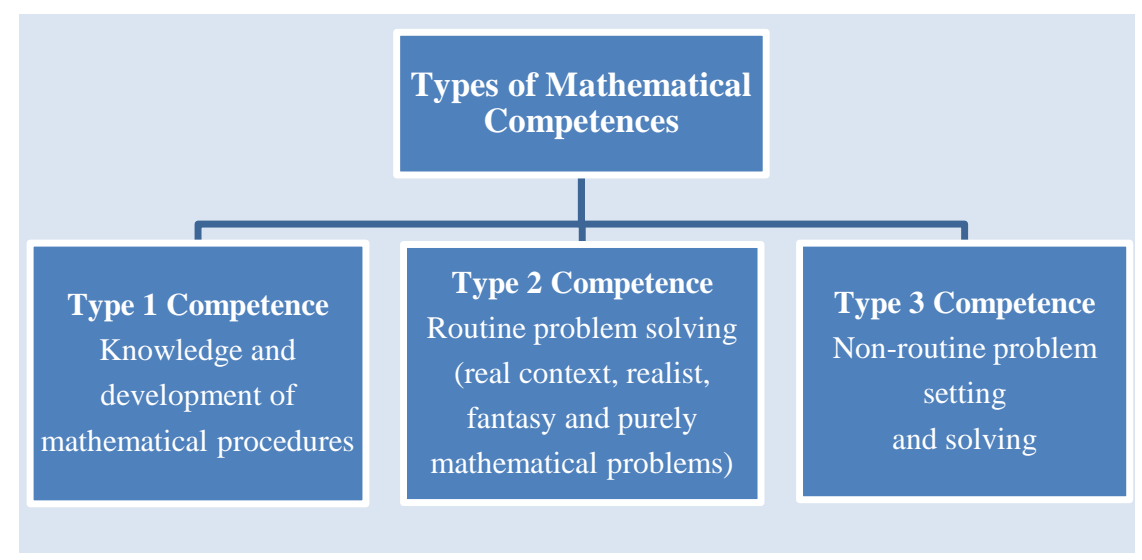

Fig. 1. Types of mathematical competences

Type 1 Competence: Knowledge and development of mathematical procedures:

This competence comprises the comprehension and command of mathematical concepts and argumentation. It consists mainly of problems that include the most common definitions or calculation problems on typical mathematical assessment. Example from the test, problem 8: "Academic performance, $\mathrm{f}(\mathrm{t})$, in an exam that takes one hour on the basis of time $\mathrm{t}$ given by $\mathrm{f}(\mathrm{t})=\mathrm{t}-\mathrm{t}^{2}, 0 \leq \mathrm{t} \leq 1$; Using logical reasoning answer: $a$ ) When 
is performance equal to zero? b) When is performance at its highest level? c) When is performance increasing or decreasing?"

Type 2 Competence: Routine problem solving:

This competence comprises suggesting, formulating, and solving routine problems in real, realistic, fantasy, and purely mathematical contexts. Routine problems are similar to those solved during instruction courses, where students follow a sequence that requires understanding the concepts and algorithms to find valid solutions.

\subsection{Context problems:}

1. Real context problems: A context is real if it occurs and triggers the students' action in that situation. Example from the test, problem 7: "Measure the sides of a sheet of paper and build a box without a lid by cutting equal squares on its corners and folding the remaining part. Determine the side where the squares must be cut in order to maximize the volume of the box."

2. Realistic context problems: A context is realistic if it feasible. It is a simulation of reality or part of it. Example from the test, problem 1: "The objective is to close a rectangular meadow using wire fence on three of its sides and flowers in the fourth one. With $800 \mathrm{~m}$. of wire fence, ¿what is the area that could be fenced with it?"

3. Fantasy context problems: A context is fantasy or fictional if it is imaginary and it is not based on reality. Example from the test, problem 4: "The speed (in $\mathrm{m} / \mathrm{s}$ ) of a Segnosaurus in a $200 \mathrm{mts}$. race is based on the distance, $x$, expressed by: $f(x)=-$ $00055 x(x-300)$. Using logical reasoning answer: a) What distance has the Segnosaurus covered when it reaches its highest speed? b) What is this speed?"

4. Purely mathematical context problems: A context is exclusively mathematical if it refers to mathematical objects: numbers, arithmetic operations and relations, geometric shapes, etc. Example problem 5 from the test (similar Type 1 Competence): "The sum of the two non-negative numbers is 36 . Find the numbers so that: a) The addition of their squares is the lowest possible number $b$ ) The addition of their square roots is the highest possible number."

Type 3 Competence: Non-routine problems setting and solving:

These competences include decoding the different ways to present mathematical situations, translating natural language to symbolic/formal language, i.e. it consists of the mathematical thinking that includes the ability to generalize. A problem will be considered as non-routine when a student does not know an answer or predetermined procedure to find it. Example from the test, problem 6: "Formulate a minimum problem where a derivative could be used" and Example from the test, problem 10: "Maximize the area of a quadrilateral inscribed in a given circle of radius 1."

It is important to mention that non-routine problems could also be classified according to their context and that the problems of competence Type 1 are generally considered in literature as similar to those of purely mathematical context. 


\section{$3 \quad$ Methodology}

This is a quantitative study of exploratory natures, since the addressed problem has been poorly studied in our current competence-based curricular context. It is of descriptive nature, as well, [46] since it analyzes point to point the role of problem solving in the process of learning of the derivative. The study sample was composed of engineering programmes at Universidad de Los Lagos. The total sample is 41 students of the fourth semester in the following engineering programmes: Food (9) Computer (13) and Business (19) that were taking the Calculus I course (Differential and Integral in one variable) during the second semester of 2018. All their curriculums are competencebased. The groups of participants were naturally formed, since they were already part of a course. Their corresponding course teachers taught all study groups. At the moment of administering the instruments, students had learned the contents of numbers and the number line, and studied the topics of limit, continuity, derivatives, and integrals. All courses had similar syllabuses where these contents were detailed. It is important to mention that students had already been assessed once on derivatives. The Levene test showed that the variances across groups are homoscedastic $($ sig $<0,005)$.

\subsection{Assessment instruments}

Diagnostic assessment: Firstly, as a diagnostic test, in all students were given a test that lasted 2 hours and 40 minutes. Its format is similar to the one they took in order to enter the higher education system in Chile in 2017 [47], which is called University Selection Test or PSU. The PSU contained multiple-choice questions with five options. Test scoring considers only correct answers.

The cognitive skills in the PSU are a reformulation and adaptation of the table of pedagogical actions from the Fundamental Objectives (OFT, for its acronym in Spanish) and the Obligatory Minimum Contents of Mathematics. The cognitive skills from the OFs have been developed through secondary education (4 years). They are in the taxonomy of [48], and include comprehension, application, analysis, synthesis, and evaluation. On the other hand, mathematical contents are grouped in 4 thematic axes: Numbers, Algebra, Geometry, Data, and Randomness. The test has 80 items. 17 of them are of Numbers; in Algebra 10 items were of algebra and 9 of functions; in Geometry, Positional Geometry and Metrics (PG) had 13 items, and Proportional Geometry (GP) 9 items; 12 of the items corresponded to Data; and 10 to Randomness. Extreme scores range from a minimum of 150 points to a maximum of 850 points. The objective of the administration of the test and evaluation of the items is to verify the abilities related to the learning of derivatives that students have in the different thematic axes before starting University.

Mathematical competences test: With the aim of assessing the performance of engineering students when solving problems associated with three types of mathematical competences and categorising the difficulties in their answers, a qualitative instrument was designed and validated through the judgment of 12 experts. The problems of the test were piloted before they were accepted for the final version. Only those with more 
than $85 \%$ of positive results were included in the final version with problems of use of derivatives that were appropriate for the level of students.

The final test was tested for reliability using Cronbach's Alpha. The result was 0.79 , which was considered acceptable considering the nature of the assessment instrument and its scope. The test had 10 open questions designed according to the classification of mathematical competences of [25], and it was administered in three two-hour sessions.

Distribution of problems $(\mathrm{P})$ is the next: $\mathrm{P} 1$, Type 2 Competence and context realistic; P2, Type 2 Competence and context fantasy; P3, Type 3 Competence and nonroutine; P4, Type 2 Competence and context fantasy; P5, Type 1 Competence; P6, Type 3 Competence non-routine; P7, Type 2 Competence and context real; P8, Type 1 Competence; P9, Type 2 Competence and context realistic and P10, Type 3 Competence non-routine.

Performance levels were established according to the stages of mathematical problem solving used by [49]. This model includes a score scale that indicates the different progress levels of students when solving a problem correctly. This four-point scale is used to record every detail in student's processes of problem solving: No Start: The student is unable to start the problem or delivers work which is meaningless ( 0 point), Focus: The student focuses the problem with a meaningful work, indicating comprehension of the problem, yet faces difficulties easily (1 point), Substance: Sufficient details show that the student has been oriented to a rational solution, yet relevant error $\mathrm{s}$ or wrong interpretations prevent the process of the correct resolution (2 points), Result: The problem is about to be resolved, yet few mistakes lead to a wrong final solution (3 points), Completion: The proper method has been used and it has led to the correct solution (4 points).

The degrees of internal discrimination were established through the biserial correlation $\left(\mathrm{r}_{\mathrm{pbis}}\right)$, which was, on average, equal to 0.41 . The difficulty for each problem and for the test as a whole was $35.1 \%$.

\section{$4 \quad$ Result}

\subsection{Diagnostic evaluation}

The specifications of the diagnostic test are presented in Table 1. The table displays the percentage of items in the diagnostic test in relation to the Thematic Axes, the percentage ranges per item of the Cognitive Skills test, and results of the diagnostic assessment. 
Table 1. Cognitive skills

\begin{tabular}{|c|c|c|c|c|c|}
\hline \multirow{2}{*}{ Thematic axes } & \multicolumn{3}{|c|}{ Cognitive skills } & \multirow{2}{*}{$\begin{array}{l}\text { Total\% } \\
\text { per item }\end{array}$} & \multirow{2}{*}{$\begin{array}{c}\text { Result } \\
\text { Diagnostic } \\
\text { Assessment }\end{array}$} \\
\hline & Comprehension & Application & $\begin{array}{c}\text { Analysis, Synthesis, } \\
\text { and Evaluation }\end{array}$ & & \\
\hline Numbers & 3 & 9 & 5 & 21,25 & $59 \%$ \\
\hline $\begin{array}{l}\text { Algebra and } \\
\text { Functions }\end{array}$ & 2 & 10 & 7 & 23,75 & $48 \%$ and $31 \%$ \\
\hline $\begin{array}{l}\text { Geometry PM } \\
\text { and Geometry } \\
\text { PR }\end{array}$ & 3 & 13 & 6 & 27,5 & $39 \%$ and $44 \%$ \\
\hline $\begin{array}{l}\text { Data and } \\
\text { Randomness }\end{array}$ & 5 & 13 & 4 & 27,5 & $50 \%$ and $47 \%$ \\
\hline Total $(\%)$ & 16,25 & 56,25 & 27,5 & 100 & \\
\hline
\end{tabular}

Following the data recorded in the country by [47] the average number of correct answers is 25 . This is equivalent to $33 \%$ of the total number of test questions. According Table 1, the highest difficulty was in functions, with $31 \%$ of achievement. In general, in the thematic axis of Algebra that includes Algebra and Functions, the achievement is $79 \%$ of all students. The thematic axis of Geometry, that includes Metric Geometry PM and Proportional Geometry PR reached 83\%; Data and Randomness has the highest achievement with $97 \%$ and the best performance is in numbers with 59\%. According to the PSU results in 2017, the percentage of achievement in the axis of Numbers is significantly higher in the subjects of the study. This might be explained by the courses students had already passed. However, the lower results in Functions, Algebra, and Geometry do not change. Regarding the thematic axis of Data and Randomness, the percentage of achievement is higher than the average of the PSU 2017 [47].

\subsection{Use of technological software}

The teaching-learning strategies include the use of technological software for the design and implementation of Calculus units, in general, and of derivatives, in particular. The tools included in the syllabi of these engineering programmes are Matlab and Derive, with objectives such as determining the partial derivatives of a function in a symbolic way, representing the gradient field and showing its geometric interpretation, etc.

One of the attributes of Matlab software is that it allows you plottin and solve the derivative of a mathematical function. Using the diff command (f) reduces the time it would take to calculate a derivative, but it does not guarantee the effective resolution of application problems of the derivative. [50] and [51] reviewed this type of software and concluded that it contributes to the development of aspects of memory and reinforces the algebraic work that takes place in classrooms. However, the visualisation of situations is left aside and, with it, the immerse construction of concepts. According to [52], reform projects with approaches that use technology have managed to retain the 
ideas of traditional calculus, but are now supported by dynamic graphics that illustrate the use of symbol manipulation to make calculations.

Therefore, it is necessary to propose to the engineering students, activities with the use of technology and that guarantee the elements of the justification of the change. Also, the derivative must be presented in a way that is natural for the student, without neglecting the symbolic part and seeking a balance between these aspects.

\subsection{Types of mathematical competences}

Fig. 2 below shows the results of the three engineering programs on each problem of the derivatives test.

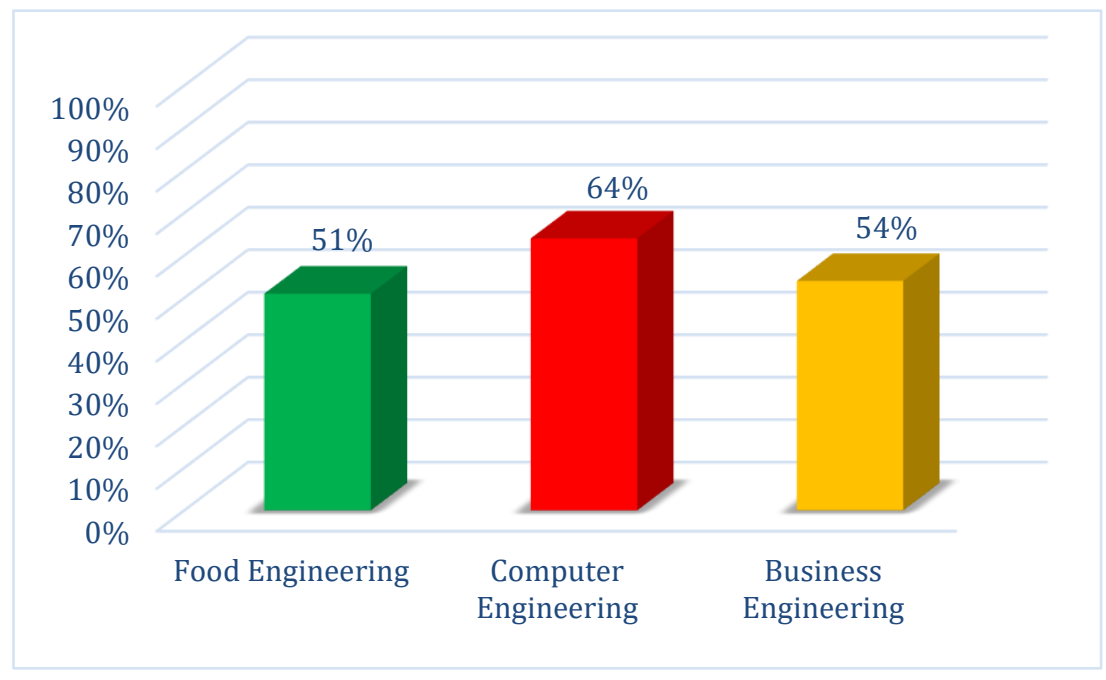

Fig. 2. Levels of performance by programs

As it can be observed in fig. 2, performance in general is $56,3 \%$ of achievement in this important topic in mathematics and the highest performance of students when solving problems of application of derivatives is on Computer Engineering, with $64 \%$ of achievement. This means that this group of engineering programmes has poor competences when solving problems that require the use of derivatives, which is one of the foundations of Differential Calculus. 


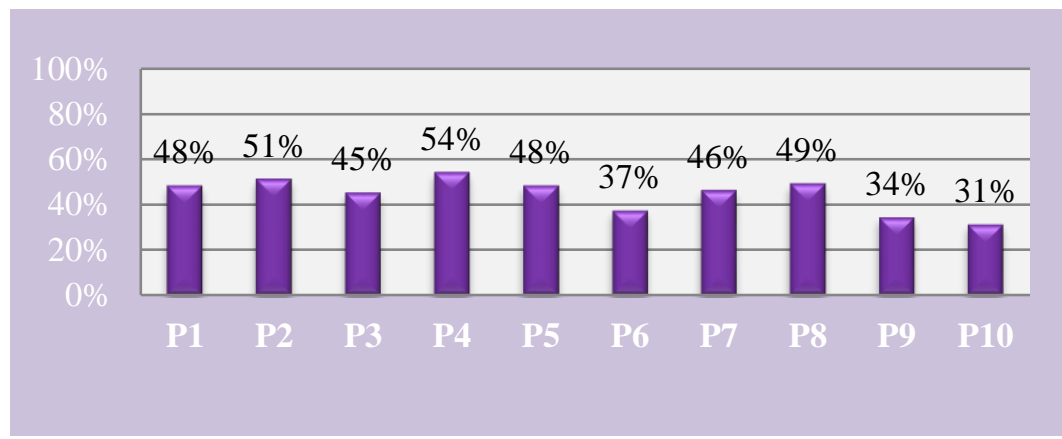

Fig. 3. Percentage of performance for each problem

As shown in fig. 3, the problems with the lowest performance are problems 10 and 9 with $31 \%$ and $34 \%$ respectively. Problem 10 corresponds to Competence Type 3 of the formulation and solving of a non-routine problem, i.e. according to own definition, the decoding of different forms of presenting mathematical situations, translating natural language into symbolic/formal language. Problem 9 corresponds to Competence Type 2 of solving routine or realistic problems, i.e. problems that are feasible because they are a simulation of reality or a part of it.

The problems with the highest achievement levels were problems 4 and 2 with $54 \%$ and $51 \%$ respectively. Both correspond to Competence Type 2 of solving routine and fantasy or fictional problems, i.e. problems that are imaginary and are not based on reality. The problem 2 and 4, is presented below.

Problem 2: "The function of $f(t)=t-2$ is that the derivative of inflation in time in one of the Seven Kingdoms of Game of Thrones, when $0 \leq t \leq 5$. Determine the value of $t$ in order to have the minimum value of inflation."

\subsection{Difficulties}

The percentages of difficulties of the participants of the three engineering programs observed in the test of problem solving with the use of derivatives are presented in fig. 4. 


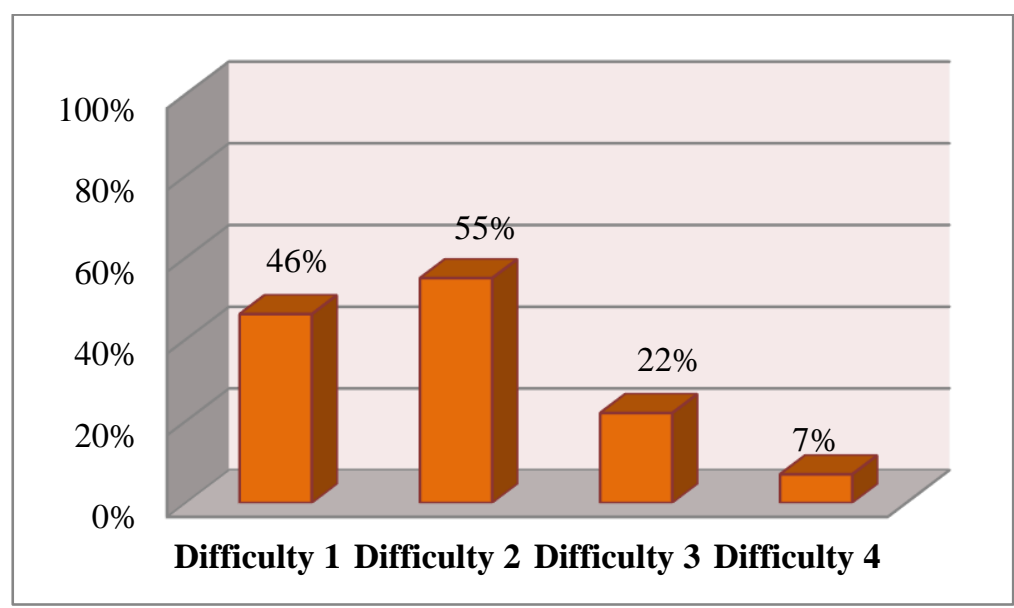

Fig. 4. Percentage of difficulties by category of the three engineering programs

According to fig. 4, 46,2\% of participants in this research had difficulties related to the complexity of mathematical objects (Difficulty 1). Different conflicts associated with comprehension and communication of the mathematical object derivative were identified in problem solving. One of these conflicts arises from the assisting role of common language in the interpretation of mathematical signs that are present in a problem statement. However, mathematical language is more precise and it is subject to exact rules. It communicates its meaning only by the exact interpretation of its signs. Our results are similar to those we have investigated in the limit of a real variable function, in which we affirm that understanding vocabulary is the most important factor in understanding several content areas, including mathematics [53].

According to [53], teaching and learning mathematics are essential for any career that requires this discipline. Learning mathematical vocabulary is a very important part of student's language development and eventually of their mathematical competence. In mathematics, students solve problems manipulating numbers and interpreting symbols, but the comprehension of mathematics requires more than knowing numbers and symbols. Mathematics also requires the development of vocabulary. Teachers and students use language to teach and learn about mathematics, and there is a myriad of specific mathematical terms in this oral and written language [54].

Regarding the difficulties associated with the mathematical thinking processes (Difficulty 2) we can say that, considering the whole test, $55 \%$ of the total sample had this difficulty. Evidence of this difficulty was observed in the fact that students were unable to follow a logical-mathematical argument.

$22 \%$ of participants had difficulties associated to the teaching processes (Difficulty 3). This difficulty was observed in the presence of ambiguous knowledge, irrelevant rules used in a messy or interchangeable way, lack of knowledge of algorithms, etc. However, it is important to mention that this research is not focused on teacher's competences. Example from the test whit this difficulty in problem 9: "In a meadow you have to enclose an area of $400 \mathrm{~m}^{2}$, which should have the shape of a rectangle. Each 
meter of fence costs $\$ 50,000$. If $x$ is the measure in meters of one of its sides, it is requested: a) Reasonably obtain the function $f$ such that $f(x)$ is the cost of the fence, indicating among which values can vary $x . b$ ) Derive reasonably the value of $x$ for which the function $f(x)$ reaches the minimum value".

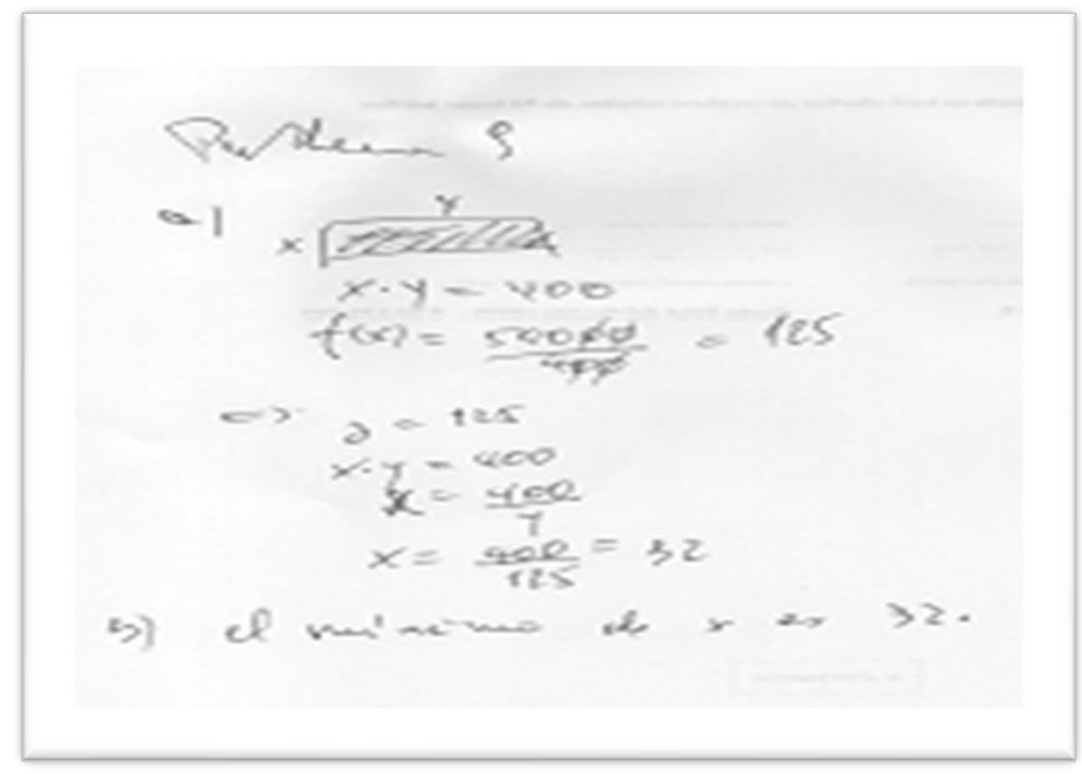

Fig. 5. Production of one student

The wrong answer of student "the minimum of $x$ is 32". Finally, only $7 \%$ of the difficulties were associated with cognitive processes (Difficulty 4). The typical reasoning observed in the problems that were solved is the expected considering the cognitive development of students in higher education. It is necessary to mention that, regardless of the results, the three study groups showed a high level of concentration during the problem-solving process and lower difficulties in basic algebra operations. The difficulties associated with the mathematics teaching processes could be observed through open questions, mainly in difficulties to remember explanations and the need of support when doubts arise. Difficulties increase with non-routine problems. Example from the test, problem 3: "Find a derivable function that has a critical point in the interval [2, 4]. ' 


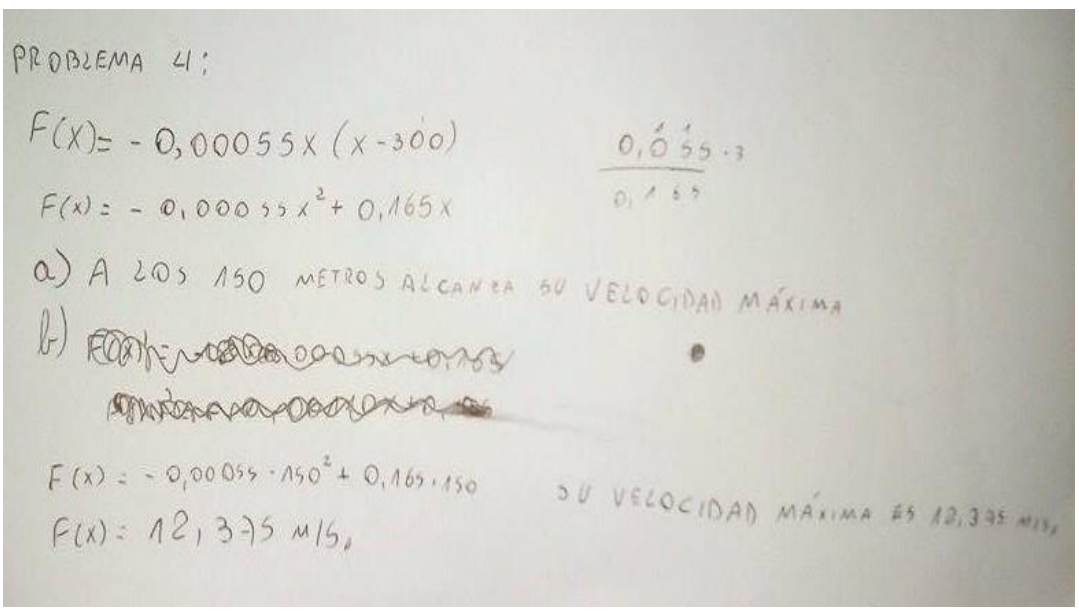

Fig. 6. Production of one student

According to Figure 6, the student does not understand the problem: "a) after 150 meters it reaches top speed, b) $\mathrm{F}(\mathrm{x})=-0,000551502+0,165150$ its maximum speed is $12,375 \mathrm{M} / \mathrm{S}$." The mechanism can be observed and that there is an attempt to respond as if it were a standard problem, rather than understanding it as a non-routine problem. The underlying difficulty is associated with teaching processes that are related to the school, the Mathematics curriculum, and the teaching methods used. They do not look for the graphical representation of the interval; they only focus on an algorithmic resolution. The development of it also presents problems in algebra, specifically in the factorization of basic algebraic expressions that must be mastered in secondary school. In most students it was possible to find evidence related to mathematical thinking processes in a strong tendency to believe that mathematics is mainly operations and algorithms instead of logical thinking as an efficient method to solve problems.

\section{Conclusion}

Based on the evidence associated with the knowledge students have prior to entering higher education, they had some difficulties with concepts related to mathematical functions, such as exponents and logarithms, which are key to manipulating equations and functions in calculus. This finding is in line with [55], who analysed students' low learning outcomes for calculus subjects and concluded that, in general, at the secondary school level, students have trouble with functions, their graphs, and algebraic manipulation.

These issues usually arise initially in algebra classes, and hinder the resolution of problems specifically associated with the dynamics of functions at intervals, the determination of maximums and minimums of a function in its broadest domain, optimization, speed estimates, and acceleration. 
Similarly, students showed lack of basic knowledge of proportional geometry, which is also in line with [56], who studied the students' difficulties in recognizing the quotient associated with the measure of relative size, and how the concepts of reason and proportion prevent students from achieving the concept of derivative.

Problem solving is of vital importance in engineering education, and our results reflect a moderate competence of students in solving application problems where the derivative must be used. Considering that the three engineering programmes have a competence-based curriculum that include problem solving, the results obtained in this research agree with [57], who claim that problems have occupied a central place in math curricula for many decades, but not problem solving.

Regarding the difficulties in problem solving, the most important one throughout the three engineering programmes corresponds to the one that involves the processes of mathematical thought (Difficulty 2). These processes are related to implicit ruptures in the different ways of thinking mathematics; the examples, drawings, and standardised images can generate errors. Our results are in line with the arguments of researchers who claim that many students cannot first achieve a pictorial image of an idea in their mind, for this reason they have difficulty understanding the concepts in mathematics [58].

Additionally, the complexity of mathematical objects (Difficulty 1) proved to be an obvious difficulty for the students of the three engineering programmes. With respect to the teaching processes developed for the learning of Mathematics that directly involves the teacher, since the teaching methods must be in accordance with the school institutional organization and the curricular sequence (Difficulty 3), although $22 \%$ was achieved of difficulty, this was reflected in the study.

Calculus texts generally include, as derivative applications, optimization problems to determine the absolute minimum and/or maximum of a function that depends on two variables, given a restriction or relationship that the two variables must always satisfy. Examples tend to focus around geometric objects, such as squares, boxes, cylinders, etc. They also have basic derivative applications in the business field, where the maximum and/or minimum value of the function is found again and the marginal cost function, the average cost, the income function, the marginal income function, and the marginal gain function are defined. However, the data from this study showed that when students of the three engineering programmes were presented with problems of derivatives in a context very little used in the books of Differential and Integral Calculation, they showed interest in addressing them and the highest level of achievement in responding to them. The problems were given a fantasy context, which it usually involves imagination and have no foundations in reality. Situations of characters from current films, and their own daily lives are examples of these fictional contexts.

Concerning the teaching processes developed to learn Mathematics that direct-ly involve the teacher; it is worth noting that teaching methods must be in accordance with the institutional organization of the school and the curricular sequence (Difficulty 3 ). In this context, although $45 \%$ difficulty was achieved, the aforementioned was reflected in the study.

According to the results, taking the calculation in high school does not guarantee success later in the calculation of the university, what is more important is to master the 
prerequisites, the algebra, the geometry and the trigonometry that lead to the calculation, which coincides with the opinion of [59] in a study conducted with more than 6,000 first year university students at 133 universities in the USA.

In summary, the investigation herein offers an approach to those contents acquired during secondary school, which could significantly have an impact on the understanding and capacity of problem solving regarding the applications of the derivatives. Additionally, this research provides a deeper understanding of those problems that are not found regularly in the literature, such as the problems with fictional contexts. If problems deal with subjects linked to the daily life of the students, there is a higher probability of being approached with success by them. The main contribution of this study has been to provide a better understanding of the deficiencies that students bring from high school in mathematics and that greatly influence engineering calculation courses, specifically in the appropriation of the concept of derivative of a function, as well as providing a different idea of how instructors can use different types of problems in their calculus courses.

\section{$6 \quad$ References}

[1] C. López, E. Aldana, and J. Erazo, "[Conceptions of teachers on the resolution of problems for the teaching of concepts of differential and integral calculus: ethnographic study]," Logos Ciencias \& Tecnología, vol.10, no.1, pp.144-156. 2018. Spanish.

[2] G. Guala, E. Güichal, A. Malet, and V. Oscherov, "[The teaching of the calculus in the polimodal education and in the university. Diagnosis on real numbers]," in Acta Latinoamerica-na de Matemática Educativa 19, G. Martínez, (Ed.), México D.F.: México, 2006, pp.303309. Spanish.

[3] A. Vega, J. Carrillo, and J. Soto, "[Analysis according to the cognitive model following constructed learning of the concept of derivative]," Bolema, vol. 28, no.8, pp.403-429. 2014.Spanish https://doi.org/10.1590/1980-4415v28n48a20

[4] L. González, and M. Radillo, "[A proposal for the teaching of the concept of derivative of a function, by means of activities of visualization]," in Acta Latinoamericana de Matemática Educativa 27, P. Leston, (Ed). Buenos Aires: Argentina, 2014, pp. 925-932. Spanish.

[5] D. Álvarez, H. Colorado, and P. Ospina, "[A methodological approach to the teaching of the concept of derivative]," Revista Científica, Edición especial, pp.201-205, 2013. Spanish.

[6] E. Irazoqui, and A.Medina, "[Preliminary study of approach to the concept of limit of a function]," Revista Theoria, vol. 22, no.1, pp.21-31, 2013. Spanish.

[7] D. Bressoud, I. Ghedamsi, and V. Martinez-Luaces, Teaching and learning of calculus. Hamburg: Springer International Publishing, 2016. https://doi.org/10.1007/978-3-319$\underline{32975-8}$

[8] M. Artigue, [The teaching of the principles of calculus: epistemological, cognitive and didactic problems]. México: Grupo Editorial Iberoamericano. 1995. Spanish.

[9] E. Ruiz, and J. Gutiérrez, "[Visualizing derivative-based problems using applications on mobile devices]," Innovación Educativa, vol. 18, no.6, pp.39-68, 2018.Spanish.

[10] J. Bezuidenhout, "Limits and continuity: Some conceptions of first year students", International Journal of Mathematical Educational in Science and Technology, vol. 32, no.4, pp.487-500, 2010. https://doi.org/10.1080/00207390010022590 
[11] V. Durand-Guerrier, and G. Arsac, "An epistemological and didactic study of a specific calculus reasoning rule", Educational Studies in Mathematics, vol. 60, no.2, pp.149-172, 2005.https://doi.org/10.1007/s10649-005-5614-y

[12] Y.Y. Ko, and E. Knuth, "Undergraduate mathematics majors' writing performance producing proofs and counter examples about continuous functions," Journal of Mathematical Behavior, vol.28, no.1, pp. 68-77, 2009. https://doi.org/10.1016/j.jmathb.2009.04.005

[13] K. Juter, "The validity of students' conceptions of differentiability and continuity, in Evaluation and comparison of mathematical achievement: dimensions and perspectives, C. Bergsten, E. Jablonka, and, M.Raman, (Eds). Sweden: Linköping University, 2012.

[14] D. Dickerson, and D. Pitman, "An examination of college mathematics majors' understandings of their own written definitions," Journal Mathematics Behavior, vol.41, no.1-9, 2016. https://doi.org/10.1016/j.jmathb.2015.11.001

[15] C. Rasmussen, K. Marrongelle, and M.C. Marcelo, "Research on calculus: what do we know and where do we need to go?" The International Journal on Mathematics Education ZDM, vol.46, no.4, pp.507-515, 2014. https://doi.org/10.1007/s11858-014-0615-x

[16] O. Swidan, and M.Yerushalmy, "Learning the indefinite integral in a dynamic and interactive technological environment," The International Journal on Mathematics Education ZDM, vol. 46, no.4, pp.517-531, 2014. https://doi.org/10.1007/s11858-014-0583-1

[17] E. Sevimli, "Understanding students' hierarchical thinking: a view from continuity, differentiability and integrability" Teaching Mathematics and its Applications, vol.37, no.1, pp.116, 2018. https://doi.org/10.1093/teamat/hrw028

[18] R. Jaafar, and Y. Lin, "Assessment for learning in the calculus classroom: a proactive approach to engage students in active learning" International Electronic Journal on Mathematics Education, vol.12, no.3, pp.503-520, 2017.

[19] A. Robert, and N. Speer. "Research on the teaching and learning of calculus/elementary analysis, in The teaching and learning of mathematics at university level, in ICMI study, D. Holton, (Ed). Holland: Kluwer Academic, 2001, pp. 283-299. https://doi.org/10.1007/0-30647231-7_26

[20] S. Vrancken, and A. Engler, "[Introduction to derivative from variation and change: research results with first year university students]," Bolema, vol. 28, no. 48, pp.449-468, 2014. Spanish. https://doi.org/10.1590/1980-4415v28n48a22

[21] A. Orton Anthony,"Students' understanding of integration, Educational Studies in Mathematics, vol.14, no.1, pp.1-18, 1983. https://doi.org/10.1007/BF00704699

[22] M.A.Tallman, M.Carlson, D. Bressoud, and M.Pearson, "A characterization of calculus I final exams in U.S. colleges and universities" International Journal Research in Undergraduate Mathematics Education, vol.2, no.1, pp.105-133, 2015. https://doi.org/10.1007/s40753$\underline{015-0023-9}$

[23] M. Cavasotto, "[Difficulties in calculation learning: what mistakes made by students can inform]," Dissertação (Mestrado), Porto Alegre: Pontifícia Universidade Católica do Rio Grande do Sul. 2010.

[24] M.M. Socas, "[Math education in medium school. difficulties, obstacles and errors in the learning of mathematics in secondary education]," in La educación matemática en la enseñanza secundaria, L. Rico (Ed). España: Editorial Horsori,1997, pp.125-152.

[25] V. Díaz, and A.Poblete Álvaro, [Longitudinal evaluation of mathematical learning, transversal objectives and context indicators]. Santiago, Chile: University of Los Lagos, National Commission for Scientific and Technological Research, 2004.

[26] V. Díaz, and A. Poblete, "[Model of professional competence of mathematics (MCPM) and its implementation in primary teachers in Chile]," Bolema, vol. 30 no.55, pp.786-807, 2016 Spanish. https://doi.org/10.1590/1980-4415v30n55a23 
[27] V. Díaz, and A. Poblete, "A model of professional competences in mathematics to update mathematical and didactic knowledge of teachers," International Journal of Mathematical Ed-ucation in Science and Technology, vol. 48 no.5, pp- 702-71, 2017. https://doi.org/10.1080/0020739X.2016.1267808

[28] L.E. Arreguín, J.Alfaro, and M.S.Ramírez, "[Development of mathematical competencies in secondary school using the project-oriented learning technique]", Revista Iberoamericana so-bre Calidad, Eficacia y Cambio en Educación, vol.10, no. 4, pp.264-284, 2012. Spanish.

[29] A. Escamilla Amparo. [The basic competences keys and proposals for its development in the centers]. Barcelona: Graó, 2008.Spanish.

[30] J. Boesen, O. Helenius, E. Bergqvist, T.Bergqvist, J. Lithner, T.Palm, and B. Palmberg, "Developing mathematical competence: from the intended to the enacted curriculum," Journal Mathematical Behavior, vol.33, pp.72- 87, 2014. https://doi.org/10.1016 /j.jmathb.2013.10.001

[31] National Council of Teachers of Mathematics NCTM: Principles and standards for school mathematics. Reston (VA): National Council of Teachers of Mathematics, 2000.

[32] A. Schoenfeld, Mathematical problem solving. Orlando: Academic Press, 2005.

[33] K. Weber, "Problem-solving, proving, and learning: the relationship between problem-solving processes and learning opportunities in the activity of proof construction," Journal Mathematical Behavior, vol. 24, no. 3, pp. 351-360, 2005. https://doi.org/10.1016/ j.jmathb.2005.09.005

[34] M. Niss, and T. H.Jensen, [Competences and mathematics learning. The Danish Agency for Education's thematic series, 18]. Denmark: The Ministry of Education Danés.pp.1-134, 2002.

[35] A. Luchin, and E. H.Luchin, Wertheimer's seminars revisited: problem solving and thinking. Albany (NY): State University of New York at Albany, 1970.

[36] M. Cooper, and S. Sandi-Urena, "Design and validation of an instrument to assess metacognitive skillfulness in chemistry problem solving," Journal of Chemical Education, vol.86, pp.240-245, 2009. https://doi.org/10.1021/ed086p240

[37] A. Kirn, and L. Benson Lisa. "Engineering students' perceptions of the future" presented at the ASEE Annual Conference \& Exposition, Seattle: Washington, 2015.

[38] M. Mccracken, and W. Newstetter, "Text to diagram to symbol: Representational transformations in problem-solving," presented at the 31st Annual Frontiers in Education Conference. Impact on Engineering and Science Education, 2001, pp. 13-17. Reno, Nevada: USA.

[39] C. Atman R. Adams E. Cardella, J.Turns, S. Mosborg, and J. Saleem, "Engineering design processes: a comparison of students and expert practitioners," Journal of Engineering Education, vol. 96, no.4, pp.359-379, 2007. https://doi.org/10.1002/j.2168-9830.2007.tb00945.x

[40] C. Baillie, E. Ko, and W. Wendy, "Advancing diverse and inclusive engineering education practices through interdisciplinary research and scholarship," Journal of Engineering Education, vol.100, no.1, pp.6-13, 2011. https://doi.org/10.1002/j.2168-9830.2011.tb00002.x

[41] M. Borrego, and L.K. Newswander, "Characteristics of successful cross-disciplinary engineering education collaborations," Journal of Engineering Education, vol. 97, no.2, pp.123134, 2006. https://doi.org/10.1002/j.2168-9830.2008.tb00962.x

[42] P. Steif Paul, J. Lobue, A.Fay, and L. Kara, "Improving problem solving performance by inducing talk about salient problem features," Journal of Engineering Education, vol. 99, no.2, pp.135-142, 2010. https://doi.org/10.1002/j.2168-9830.2010.tb01050.x

[43] R. E.Mayer, "Cognitive, metacognitive, and motivational aspects of problem solving," Instructional Science, vol. 26, no. 1, pp.49-63, 1998. 
[44] Ministerio de Educación de Chile MINEDUC, [PISA mathematical competences: a requirement for the information society]. Santiago: Agencia de Calidad de la Educación, MINEDUC, 2013. Spanish.

[45] V. Díaz, "Problem solving in Chilean higher education: figurations prior in interpretations of cartesian graphs," International Journal of Social, Behavioral, Educational, Economic, Business and Industrial Engineering, vol. 11, no.2, pp.332 - 340, 2017.

[46] R. Sampieri, [Investigation Methodology]. México: Mc Graw Hill, 2014. Spanish.

[47] Departamento de Evaluación, Medición y Registro Educacional (DEMRE), [Admission process model 2017]. Santiago: Editorial Universidad de Chile, 2018. Spanish.

[48] B. Bloom, Taxonomy of educational objectives: The classification of educational goals: Cog-nitive Domain. London: Longman, 1956.

[49] A. Poblete, and V. Díaz, "[Solve types of mathematical problems: a disabling skill?]," Revista Epsilon, vol.14, no.42, pp.409-423, 1998. Spanish.

[50] J.J.Gutiérrez [Mobile system as a support tool for calculation learning. case study functions], Master's Thesis. México: Escuela Superior de Cómputo IPN, 2013. Spanish.

[51] E. Ruiz, J. Gutierrez, and L. Garay, "[Visualizing derivative-based problems using applications on mobile devices]," Innovación Educativa, vol.18, no.76, pp.39-68, 2018. Spanish.

[52] D.Tall, [An approach sensitive to Calculus], in [The teaching of differential and integral calculus], A.Cuevas, (Ed). México: Pearson, 2013, pp.127-134. Spanish.

[53] V. Díaz, and A. Poblete, "[Mathematical competences: performance and errors in problem solving]," Revista Paradigma, vol.XL, no.1, pp. 358-383, 2019. Spanish.

[54] P. J. Riccomini, J. Hwang, and S.Morano, "Developing mathematical problem solving through strategic instruction: much more than a keyword," Esmerald Insigth, vol.29, pp.3960, 2016. https://doi.org/10.1108/S0735-004X20160000029003

[55] S.R.Powell, and N. Gena, "An investigation of the mathematics-vocabulary knowledge of first-grade students," The Elementary School Journal, vol.117, no.4, pp. 664-686, 2017. https://doi.org/10.1086/691604

[56] Y. Siti, "Analysis of difficulty learning calculus subject for mathematical education students," International Journal of Scientific \& Technology Research, vol. 8, no. 3, pp. 80-84, 2019.

[57] C. Byerley, N. Hatfield, and P. Thompson, "Calculus students' understandings of division rate and derivative, presented at the 15th Annual Conference on Research in Undergraduate Mathematics Education, 2012, pp. 358-363, Portland: Oregon.

[58] G. M. Stanic and J. Kilpatrick, Historical perspectives on problem solving in the mathematics curriculum, In The Teaching and Assessing of Mathematical Problem Solving, C. Randall, and S. Edward, (Ed). Reston (VA): National Council of Teachers of Mathematics, 1989, pp.1-22.

[59] P.M. Sadler, and G. Sonnert, "The path to college calculus: The impact of high school mathematics coursework," Journal for Research in Mathematics Education, vol. 49, no.3, pp. 292329, 2018. https://doi.org/10.5951/jresematheduc.49.3.0292

\section{Author}

Verónica Díaz Quezada, has PhD in Education with Mathematical Specialisation. Master's Degree in Educational Evaluation and Secondary Mathematics Teacher. From 1999, Veronica has been senior lecturer and researcher in the Department of Exact Sciences at Universidad de Los Lagos in Chile. Her Research is from university education in mathematics pedagogy and in diverse engineering, in areas of algebra, differential 
calculus, arithmetic and geometry. She has an active participation in research projects, as principal researcher or co-researcher, both in national projects of the National as well as international projects. These researches have been published in indexed journals, as well as lecturer on the subjects researched, in Chile and abroad. Mathematical Consultant for UNESCO in the Latin American Laboratory for the Evaluation of Educational Quality and Undergraduate and Graduate Evaluator for the National Accreditation Commission CNA for universities in Chile.

Article submitted 2019-11-22. Resubmitted 2020-03-02. Final acceptance 2020-03-12. Final version published as submitted by the authors. 